\title{
Photochromism and Dual-Color Fluorescence Polyoxometalate-benzospiropyran Molecular Switch
}

\author{
[a] Dr. A. Parrot, A. Bernard, Dr. A. Jacquart, Dr. E. Derat, Prof. A \\ Proust, Dr. G. Izzet \\ Institut Parisien de Chimie Moléculaire UMR CNRS 8232 \\ Sorbonne Universités, UPMC-Paris06, \\ 4 Place Jussieu, F-75005 Paris, France \\ E-mail: guillaume.izzet@upmc.fr \\ [b] Dr. S. A. Serapian, Prof. C. Bo \\ Catalan Institute of Chemical Research (ICIQ) \\ The Barcelona Institute of Science and Technology \\ Avinguda dels Països Catalans 16, 43007 Tarragona, Spain \\ [c] Dr. O. Oms, Dr. A. Dolbecq, Prof. P. Mialane, \\ Institut Lavoisier de Versailles, UMR CNRS 8180 \\ Université de Versailles Saint-Quentin en Yvelines, \\ Université Paris Saclay, \\ 45 Avenue des Etats-Unis, F-78035 Versailles cedex, France \\ E-mail: pierre.mialane@uvsq.fr \\ [d] Dr. R. Métivier \\ PPSM, UMR CNRS 8531 \\ ENS Cachan \\ 61 av. Président Wilson, 94235 Cachan cedex France
}

\author{
Arnaud Parrot, ${ }^{[\mathrm{a}]}$ Aurélie Bernard, ${ }^{[\mathrm{a}]}$ Aurélie \\ Jacquart, ${ }^{[a]}$ Stefano Artin Serapian, ${ }^{[b]}$ Carles \\ Bo, ${ }^{[b]}$ Etienne Derat, ${ }^{[a]}$ Olivier Oms, ${ }^{[c]}$ Anne \\ Dolbecq, ${ }^{[c]}$ Anna Proust, ${ }^{[a]}$ Rémi Métivier, ${ }^{[d]}$ \\ Pierre Mialane, ${ }^{*[c]}$ and Guillaume Izzet ${ }^{*[c]}$
}

\begin{abstract}
The photophysical properties of a Keggin-type polyoxometalate (POM) covalently bounded to a benzospiropyran (BSPR) unit have been investigated. These studies reveal that (i) both closed and open forms are emissive with distinct spectral features $\left(\lambda_{\text {em, }}(\right.$ closed form) $=$ $530 \mathrm{~nm}, \lambda_{\mathrm{em}}$, (open form) $=670 \mathrm{~nm}$ ); (ii) the fluorescence of the BSPR unit of the POM-based hybrid is considerably enhanced compared to BSPR reference compounds. While the fluorescence excitation energy of the BSPR reference compounds ( $370 \mathrm{~nm}$ ) is close to the intense absorption responsible of the photochromic character (350 nm), the fluorescence excitation of the hybrid is shifted to lower energy (400 nm), facilitating the population of the emissive state. Combined NOESY NMR and theoretical calculations of the closed form of hybrid give an intimate understanding of the structural conformation adopted by the hybrid and show that the nitro-aryl moieties of the BSPR is folded toward the POM, which should affect the electronic properties of the BSPR.
\end{abstract}

Photo-responsive molecules and materials are currently receiving considerable attention regarding their potentiality for the development of advanced photonic devices in various applications such as information storage, optical switches, protection, smart labelling and super-resolution microscopy. ${ }^{[1]}$ Particularly, the elaboration of molecular systems combining photo-switching and fluorescence properties constitute a promising research field because of the high sensitivity, resolution, contrast and fast response times of the fluorescence. Furthermore, the emergence of single-molecule fluorescence spectroscopy opens the route to high memory density nanodevices, in which a single molecule would work as one bit of memory, ${ }^{[2]}$ and thus strongly supports the molecular approach. Until now, the development of molecular systems displaying photo-modulated emissive properties has mostly relied on the association of luminescent and photochromic components in a molecular assembly. ${ }^{[3]}$ In these systems, the transformation of the photochromic component is exploited to modulate the emission intensity of the luminescent component on the basis of electron and/or energy transfer. ${ }^{[4]}$ However, molecular systems displaying tuneable fluorescence features, i.e. having different emission energies, according to the form of the photochromic unit, have been scarcely reported in the literature. ${ }^{[5]}$ The coexistence of photochromic and fluorescence properties, in a single photoactive unit, is rarely achieved since in case of fast internal conversion only one photophysical property (photochromic vs fluorescence) is observed. Furthermore the ns timescale of fluorescence ${ }^{[6]}$ is considerably slower than the fs to ps timescale of the ring opening/closure dynamics occurring in the photochromic events. ${ }^{[7]}$

POMs are nanosized molecular oxo cluster that are currently receiving considerable attention because of their wide range of properties and their potential applications in various fields such as analytical chemistry, medicine and catalysis, but also optics. ${ }^{[8],[9]}$ Noticeably, efficient modulation of the emission intensity of $\mathrm{a} \mathrm{Eu}^{3+}$ center embedded in a purely inorganic POM compound has been 
reached by photo-reduction of the polyoxotungstate framework. ${ }^{[10]}$ On another hand, spiropyrans constitute an important class of photochromic organic compounds. ${ }^{[1]}$ Recently, a quenching of the luminescence of the BODIPY fragment in a photochromic spiropyran-polyoxomolybdate-BODIPY complex has been evidenced. ${ }^{[12]}$ But systems - incorporating POM or not - with different emission energies remain largely to be developed.

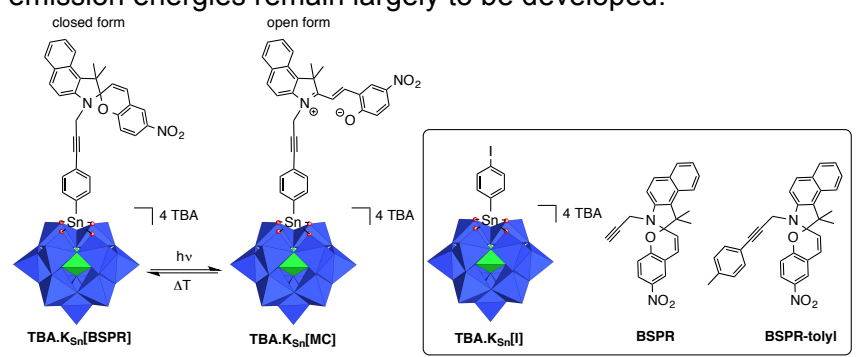

Figure 1. Photoisomerization process occurring in the organo-tin POM hybrid $\mathbf{K}_{\mathbf{s n}}$ [BSPR]. Framed: Molecular representation of the reference compounds $\mathbf{K}_{\mathbf{S n}}[\mathbf{l}]$, BSPR and BSPR-tolyl described in this study

We previously described the synthesis and photochromic properties (both in solution and in the solid state) of a new family of polyoxometalate (POM)-based organic/inorganic hybrids, in which polyoxotungstates are covalently linked to a spiropyran or a benzospiropyran unit. ${ }^{[13]}$ The $\mathbf{K}_{\mathbf{S n}}[\mathbf{B S P R}]^{[14]}$ compound (Figure 1) is illustrative of the materials reported in the study mentioned above, and can be described as a tin-monosubstituted Keggin $\left[\mathrm{PW}_{11} \mathrm{O}_{39} \mathrm{Sn}\right]^{4-}$ anion covalently connected to a benzospiropyran entity. We herein report that this complex displays significant fluorescence properties under near visible irradiation while the starting benzospiropyran is scarcely luminescent. More importantly, in this hybrid, it is demonstrated that the organic photochromic unit is emissive in both isomeric forms, with distinct emissive features, while retaining its photochromic properties. The enhanced fluorescence of the closed form arising from the covalent combination of organic and inorganic components is tentatively rationalized thanks to a computational study.
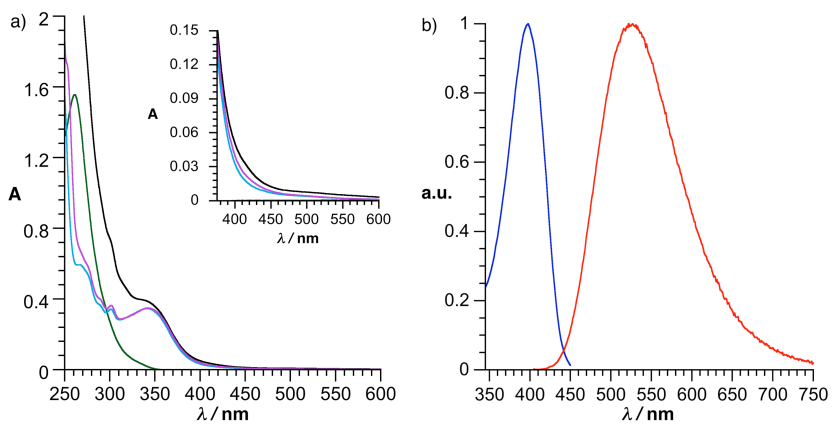

Figure 2. (a) UV-vis absorption spectra recorded for $\mathbf{K}_{\mathrm{sn}}[\mathbf{B S P R}]$ (black), the starting POM platform $\mathbf{K}_{\mathrm{sn}}[\mathbf{l}]$ (green) and the benzospiropyran references $\mathbf{B S P R}$ (blue) and BSPR-tolyl (purple) in $3.10^{-5} \mathrm{M}$ acetonitrile solution. Insert: enhancement of the absorption spectra in the $380-650 \mathrm{~nm}$ range. (b) Emission (red, $\lambda_{\text {exc }}=$ $400 \mathrm{~nm}$ ) and excitation spectra (blue, $\lambda_{\mathrm{em}}=530 \mathrm{~nm}$ ) of $\mathbf{K}_{\mathrm{Sn}}[\mathrm{BSPR}]$ in acetonitrile solution.

The synthesis and electrochemical properties of $\mathbf{K}_{\mathbf{S n}}[\mathrm{BSPR}]$ have been previously reported. ${ }^{[13]}$ For the present study we also designed a new benzospiropyran reference compound named BSPR-tolyl in order to have the most accurate benzospiropyran reference to the POM-based hybrid $\mathbf{K}_{\mathbf{S n}}$ [BSPR]. The synthesis of BSPR-tolyl involves a Sonogashira cross-coupling reaction between the alkyne-terminated BSPR compound with 4-iodotoluene.

Between 250 and $350 \mathrm{~nm}$, the absorption spectrum of $\mathbf{K}_{\mathbf{S n}}$ [BSPR] displays intense absorption bands attributed to both oxygen-tometal charge transfer bands localized on the POM (ca. $270 \mathrm{~nm}$ ) and $\pi \rightarrow \pi^{*}$ transitions localized on the organic unit (Figure 2a). Above $350 \mathrm{~nm}$, the absorption spectrum of $\mathbf{K}_{\mathbf{S n}}$ [BSPR] is mostly dominated by the benzospiropyran unit, since the POM itself does not contribute to the spectral profile in the visible. Finally, around $400 \mathrm{~nm}, \mathbf{K}_{\mathbf{S n}}$ [BSPR] has a weak absorption that is even higher than those of the reference compounds BSPR and BSPR-tolyl (Figure 2a (insert)). In acetonitrile (MeCN) solution, $\mathbf{K}_{\mathbf{S n}}$ [BSPR] exhibits a prominent emission band at $\lambda_{\text {em }}=530 \mathrm{~nm}(\phi=4.0 \%$, Figure $2 \mathrm{~b})$ when excited in the UV-visible spectrum down to at least $350 \mathrm{~nm}$. The excitation spectrum of $\mathbf{K}_{\mathrm{Sn}}$ [BSPR] at $\lambda_{\mathrm{em}}=530 \mathrm{~nm}$ in MeCN exhibits a broad absorption between $350 \mathrm{~nm}$ and $450 \mathrm{~nm}$ with a maximum at $400 \mathrm{~nm}$ (Figure $2 \mathrm{~b}$ ) matching with the previously mentioned slight absorption at ca. $400 \mathrm{~nm}$. As regards the reference compounds, BSPR and BSPR-tolyl display a weaker emission with a slight hypsochromic shift $(\phi(\mathbf{B S P R})=0.6 \%, \phi(\mathbf{B S P R}$-tolyl $)=$ $1.5 \%$ ). Furthermore, their excitation spectra exhibit a maximum at higher energy (i.e. $370 \mathrm{~nm}$, Figure S4). Finally the fluorescence lifetime of the POM-based hybrid $\mathbf{K}_{\mathbf{s n}}$ [BSPR] and the reference compound BSPR-tolyl are similar with $\tau \approx 8-9$ ns, suggesting that 
the presence of the tolyl group or the POM do not affect the radiative/nonradiative rate constants of the emitting state. These findings indicate that the nature of the emissive state of all compounds is identical and thus centred on the BSPR unit. All photophysical data are reported in Table 1.

Table 1. Photophysical data of the compounds in $\mathrm{MeCN}$ solutions

\begin{tabular}{lllll}
\hline Head 1 & $\lambda_{\text {em,max }}, \mathrm{nm}$ & $\lambda_{\text {exc,max }}, \mathrm{nm}$ & $\tau, \mathrm{ns}$ & $\phi^{[\mathrm{a}]}$ \\
\hline TBA.K & 528 & 400 & 8.9 & $4 \pm 1 \%$ \\
BSPR-tolyl & 512 & 370 & 8.4 & $1.5 \pm 0.4 \%$ \\
BSPR & 517 & 370 & n.c. & $0.6 \pm 0.2 \%$ \\
\hline
\end{tabular}

[a] Quantum yields were recorded with an excitation wavelength corresponding to the maximum of the excitation spectrum.

The photochromic properties of $\mathbf{K}_{\mathbf{S n}}$ [BSPR] have been studied in solution. In its closed form, the colourless benzospiropyran molecule contains a $\mathrm{C}_{\text {spiro- }} \mathrm{O}$ bond, which can be cleaved under near-UV irradiation, leading to a zwitterionic merocyanin (MC) isomer (Figure 1). As the MC form is unstable in acetonitrile at room temperature, the photogeneration of the open form was performed at $30^{\circ} \mathrm{C}$ where both isomeric forms of the benzospiropyran units are kinetically stable. Under UV irradiation $\left(335 \mathrm{~nm}, 12 \mathrm{~mW} . \mathrm{cm}^{-2}\right)$, the colourless solution of $\mathbf{K}_{\mathbf{S n}}$ [BSPR] in MeCN quickly shifts to purple with two absorption bands in the visible region, at $400 \mathrm{~nm}$ and 585 $\mathrm{nm}$, attributed to the appearance of the $\mathrm{MC}$ form, and reaches maximum coloration after 40 min of irradiation (Figure 3a). By comparison, these bands arise at similar wavelengths for an irradiated BSPR solution. ${ }^{[13]}$ When the irradiation is performed at higher wavelength $(365 \mathrm{~nm})$, similar absorption appears, albeit less intense (Figure S5), indicating that in the photostationary state, the open form vs closed form ratio is lower using lower energy wavelength. The purple sample is stable at temperature below $-10^{\circ} \mathrm{C}$ but quickly decolours when warming to room temperature. The intensity of the fluorescence at $530 \mathrm{~nm}$ decreases upon photo-irradiation while a new emission band at $670 \mathrm{~nm}$, attributed to the emission of the MC form as reported in the literature, ${ }^{[3 a, 15]}$ concomitantly appears (Figure 3b).
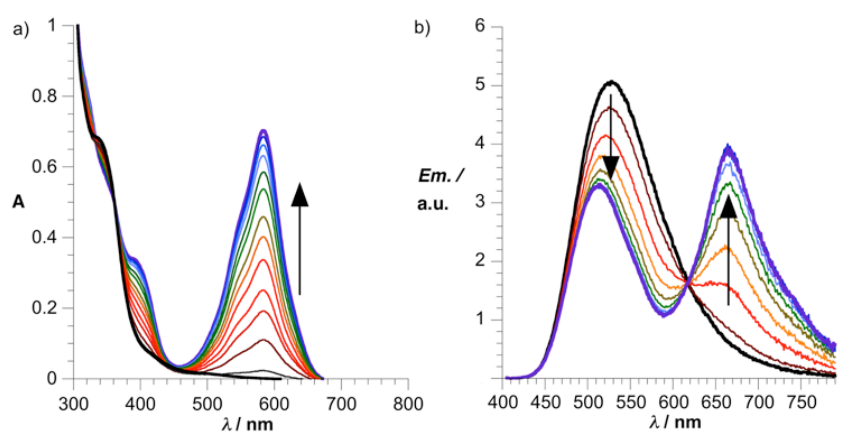

Figure 3. UV-vis absorption (a) and emission (b) spectral changes of $\mathbf{K}_{\mathrm{Sn}}$ [BSPR] in acetonitrile solution $\left(4.10^{-5} \mathrm{M}, T=-30^{\circ} \mathrm{C}\right)$ during photoirradiation (335 nm). Black curves correspond to the spectra of $\mathbf{K}_{\mathbf{S n}}$ [BSPR] before irradiation; purple curves correspond to the spectra of the sample in the photolysis steady-state.

When warming to room temperature, the fluorescence of the closed form at $530 \mathrm{~nm}$ is almost retrieved with a ca. $8 \%$ decrease indicating that a slight decomposition may occur during the photolysis (Figure S6).

In order to understand the role of the POM in the enhanced fluorescence of $\mathbf{K}_{\mathbf{S n}}$ [BSPR] compared to the reference BSPR compounds, we performed a series of theoretical calculations using density functional theory (DFT). As a wide range of conformers resulting from the rotation of the benzospiropyran unit around the methylene linker are potentially accessible, we undertook a $2 \mathrm{D}$ ${ }^{1} \mathrm{H} /{ }^{1} \mathrm{H}$ NOESY NMR study of both BSPR-tolyl and $\mathbf{K}_{\mathbf{S n}}[\mathbf{B S P R}]$ in $\mathrm{CD}_{3} \mathrm{CN}$ to establish their spatial organization. The ${ }^{1} \mathrm{H}$ NMR spectra $(600 \mathrm{MHz}, 300 \mathrm{~K})$ of $\mathbf{K}_{\mathbf{S n}}$ [BSPR] and BSPR-tolyl display a unique set of signals with sharp peaks. The NOESY NMR spectra of BSPR-tolyl (Figure S2) and $\mathbf{K}_{\mathbf{S n}}$ [BSPR] (Figure S3) displays same NOE correlations involving $\mathrm{H}_{3} / \mathrm{H}_{9}, \mathrm{H}_{3} / \mathrm{H}_{9}, \mathrm{H}_{3} / \mathrm{H}_{10}, \mathrm{H}_{3} / \mathrm{H}_{10}, \mathrm{H}_{3} / \mathrm{H}_{11}$ and $\mathrm{H}_{2} / \mathrm{H}_{14}$ proton pairs (Figure 4). This indicates that the benzospiropyran unit of BSPR-tolyl and $\mathbf{K}_{\mathbf{s n}}$ [BSPR] adopts a similar conformation in which the nitroaryl moiety is folded and engages $\mathrm{C}-\mathrm{H} / \pi$ interactions with the tolyl/aryltin unit. Furthermore, it also implies that, in $\mathbf{K}_{\mathbf{S n}}$ [BSPR], the POM has little effect on the spatial organization of the benzospiropyran unit and that the enhancement of the fluorescence emission in the hybrid most likely does not arise from a conformational change of the benzospiropyran unit. Quantitative analysis of 2D NOE cross-peaks of the above protons allows to derive the distances separating them (Table S1). We observe that the nitroaryl moieties is slightly more folded in $\mathbf{K}_{\mathbf{s n}}$ [BSPR] than in BSPR-tolyl. While BSPR display two chirality centres $\left(\mathrm{C}_{\text {spiro }}\right.$ and $\left.\mathrm{N}\right)$, BSPR-tolyl and $\mathbf{K}_{\mathbf{s n}}$ [BSPR] exists as two potential sets of diastereoisomers. Nonetheless, circular dichroism experiments of BSPR-tolyl and $\mathbf{K}_{\mathbf{S n}}$ [BSPR] showed no signals, pointing to equal stereoisomer population in solution. 
DFT energy-optimized structures of BSPR-tolyl and $\mathbf{K}_{\mathbf{S n}}$ [BSPR] were then obtained starting from input structures in which the BSPR unit display a folded geometry towards the tolyl/aryltin unit. Whereas we only considered one type of chirality at the $\mathrm{C}_{\text {spiro }}$ centre, we considered both possible inversions of the $\mathrm{N}$ centre, thus generating the diastereoisomer pairs $\mathrm{K}_{\mathrm{Sn}}$ [BSPR].1 / $\mathrm{K}_{\mathrm{Sn}}[\mathrm{BSPR}] .2$, and BSPR-tolyl.1 / BSPR-tolyl.2 (Table S1 and on-line). ${ }^{* *}$ iochemBD reference $e^{* * *}$

At the level of theory used in our calculations, in both pairs of diastereoisomers the .2 partner is always found to exhibit greater energetic stability: $\mathbf{K}_{\mathrm{sn}}$ [BSPR].2 is more stable than $\mathbf{K}_{\mathrm{sn}}$ [BSPR].1 by $2.78 \mathrm{kcal} \mathrm{mol}^{-1}$; whereas BSPR-tolyl.2 is more stable than BSPR-tolyl. 1 by $2.28 \mathrm{kcal} \mathrm{mol}^{-1}$.

We observe that for all structures the $\mathrm{H}-\mathrm{H}$ distances are in good agreement with the experimental distances obtained from the $2 \mathrm{D}$ ${ }^{1} \mathrm{H} /{ }^{1} \mathrm{H}$ NOESY NMR spectra (except $\mathrm{H}_{3} / \mathrm{H}_{10}$ for which a ca. $0.6 \AA$ discrepancy is calculated). Consequently no proton-proton distance constraints were further input into these structures.
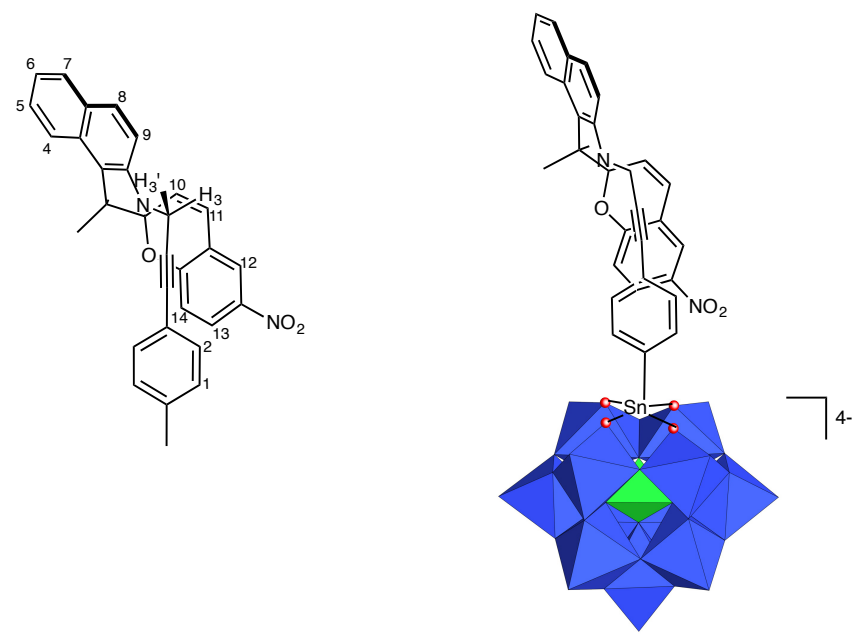

Figure 4. Representation of energy-optimized structures of BSPR and $\mathbf{K}_{\mathrm{Sn}}[\mathrm{BSPR}]$.

Subsequently, time-dependent DFT (TD-DFT) calculations were performed on energy-optimized structures of $\mathbf{K}_{\mathrm{Sn}}[\mathrm{BSPR}$.1 / $\mathrm{K}_{\mathrm{sn}}$ [BSPR].2 and the benzospiropyran references BSPR-tolyl.1 / BSPR-tolyl.2 and BSPR.1 / BSPR.2. The calculated UV-visible absorption spectra of all compounds are dominated by intense bands around $350 \mathrm{~nm}$, in agreement with the experimental spectra. However despite a minor transition at ca. $450 \mathrm{~nm}$ corresponding to a BSPR (HOMO) $\rightarrow$ BSPR (LUMO) transition, we did not observe additional bands in the $370-400 \mathrm{~nm}$ region that could be attributed to a transition populating the BSPR emitting state. Owing to the molecular complexity of the hybrid, it appears thus complicated to accurately model the effect of the POM on the electronic properties of the BSPR in $\mathbf{K}_{\mathrm{Sn}}$ [BSPR]. Yet both the fluorescence maximum energy and the fluorescence excitation maximum energy of $\mathbf{K}_{\mathbf{S n}}[\mathbf{B S P R}]$ are slightly red-shifted compared to BSPR reference compounds. This suggests that the electronic properties of the BSPR moiety are affected by the POM, which is located in its vicinity because of the folding of the nitroaryl ring. This minor energy shift has significant consequences, since the absorption responsible for the fluorescence is less hindered by the intense absorption at ca. $350 \mathrm{~nm}$ that is responsible of the photochromic behaviour of the BSPR. The fluorescence lifetime of all BSPR compounds being similar, the difference in the emission intensity between the hybrid and the reference compounds mostly arises from a greater population of the emitting state in $\mathbf{K}_{\mathbf{S n}}$ [BSPR]. In both photochromic forms of the BSPR, the excitation energy leading to the emitting state is lower than that of the excitation leading to photochromism reactions. This favours the coexistence of photochromic and fluorescence properties since the dynamics of the photochromic events are known to be much faster that the fluorescence decay. In this respect, further computational studies should be undertaken on $\mathbf{K}_{\mathbf{S n}}$ [BSPR] and the two reference systems, with particular focus on the energetics of the open MC forms, and those of the first singlet excited state previously reported by Celani et al. ${ }^{[16]}$

In conclusion we have described an unprecedented example of a molecular photoswitch based of a covalent POM-BSPR conjugate that displays specific fluorescence features in each of its two-photochromic forms. Interestingly, the fluorescence of the closed form of the hybrid is significantly higher than that of reference BSPR compounds. This is attributed to a more easily accessible emitting state in the hybrid, likely due to a folding of the BSPR towards the POM. This system opens new insights for the development of molecular optical switches.

\section{Experimental Section}


Experimental Details. Acetonitrile was obtained from commercial sources and used as received. $\mathbf{K}_{\mathbf{S n}}[\mathbf{l}]$, $\mathbf{K}_{\mathbf{S n}}$ [BSPR] and $\mathbf{B S P R}$ were synthesized according to the literature procedure. ${ }^{[13,17]}$ Photolysis reactions were performed with a Hg/Xe lamp (Hamamatsu, LC6 Lightningcure, 150 W) equipped with filters of appropriate wavelengths. UV-visible spectra were recorded on a Agilent Cary5000 spectrophotometer connected to a Hellma $661.202-U V$ all-quartz immersion UV-visible probe (10 mm optical path length) via a Hellma 662.000-UV/NIR Fibre-Optic Cable Interface and $2 \mathrm{~m}$ long 041.102-UV quartz optic fibres. Fluorescence spectra of solutions were obtained on a Horiba Jobin Yvon FluoroLog-3 spectrofluorometer. Low temperature fluorescence measurements were made with an Oxford Instruments Optistat DN cryostat. All NMR experiments were performed on a Bruker Avance III $600 \mathrm{MHz}$ equipped with a $5 \mathrm{~mm}$ z-gradient broad-band fluorine observation (BBFO) probe in $\mathrm{CD}_{3} \mathrm{CN}$. The intensity of the crosspeaks in the ${ }^{1} \mathrm{H} /{ }^{1} \mathrm{H}$ NOESY experiments were calibrated using the crosspeak for $\mathrm{H}_{11} / \mathrm{H}_{12}$ correlation as an internal standard, as this internuclear distance is known. The distances were then calculated using a $1 / r^{6}$ dependence.

Theoretical calculations. All calculations discussed in this work were carried out using the Gaussian09 package. ${ }^{\text {[18] }}$ Closed-shell DFT optimizations of all structures (constrained and unconstrained) were carried out using the PBE0 density functional; ${ }^{[19]}$ in conjunction with Grimme's D3 dispersion corrections $^{[20]}$ and Becke-Johnson damping ${ }^{[21]}(-\mathrm{D} 3(\mathrm{BJ}))$ to more accurately model dispersion effects (particularly in aromatic and alkynylic components of the BSPR moieties). At this stage, electrons on oxygen, carbon, hydrogen, phosphorus, and nitrogen atoms were modeled using the D95 basis set $^{[22]}$ with an extra $d$ polarization function (as implemented by Gaussian09); on the other hand, tin and tungsten electrons were modeled, respectively, with the MWB46 ${ }^{[23]}$ and MWB60 ${ }^{[24]}$ effective core potentials (ECPs) and basis sets. Single-point TD-DFT calculations on resulting structures were carried out using the methodology previously described by Deblonde et al. for deriving spectra of POMs: ${ }^{[25]}$ the PBE0-D3(BJ) functional was retained, but this time all electrons were modelled using the def2TZVP ECP and basis set. ${ }^{[26]}$ In all cases, solvent effects (acetonitrile) were implicitly taken into account using the polarizable continuum model. ${ }^{[27]}$ All calculations are available on-line. ${ }^{* \star *}$ iochemBD reference ${ }^{* \star *}$

Keywords: molecular photoswitch $\bullet$ polyoxometalates $\cdot$ photochromism $\bullet$ emerging property $\bullet$ density functional calculations.

[1] a) M. Natali, S. Giordani, Chem. Soc. Rev. 2012, 41, 4010-4029; b) H. Dürr, H. Bouas-Laurent, Photochromism: Molecules and Systems, Elsevier, Amsterdam, 2003; c) B. L. Feringa, Molecular Switches, Wiley-VCH, 2001.

[2] M. Irie, T. Fukaminato, T. Sasaki, N. Tamai, T. Kawai, Nature 2002, 420, 759-760.

[3] a) T. Fukaminato, J. Photochem. Photobiol., C 2011, 12, 177-208; b) Y. Hasegawa, T. Nakagawa, T. Kawai, Coord. Chem. Rev. 2010, 254, 2643-2651.

[4] I. Yildiz, E. Deniz, F. M. Raymo, Chem. Soc. Rev. 2009, 38, 1859-1867.

[5] a) T. Fukaminato, T. Hirose, T. Doi, M. Hazama, K. Matsuda, M. Irie, J. Am. Chem. Soc. 2014, 136, 17145-17154; b) H. H. Liu, Y. Chen, J. Phys. Chem. A 2009, 113, 5550-5553; c) Z. Y. Tian, W. W. Wu, W. Wan, A. D. Q. Li, J. Am. Chem. Soc. 2009, 131, 4245-4252; d) C. C. Lin, C. C. Hsieh, Y. C. Yu, C. H. Lai, C. N. Huang, P. Y. Kuo, C. H. Lin, D. Y. Yang, P. T. Chou, J. Phys. Chem. A 2009, 113, 9321-9328.

[6] Principles of Fluorescence Spectroscopy, 3rd Edition, J. R. Lakowicz ed., Springer-Verlag, New York, 2006.

[7] a) J. Ern, A. Bens, H. D. Martin, S. Mukamel, D. Schmid, S. Tretiak, E. Tsiper, C. Kryschi, J. Lumin. 2000, 87-9, 742-744; b) J. Kohl-Landgraf, M. Braun, C. Ozcoban, D. P. N. Goncalves, A. Heckel, J. Wachtveitl, J. Am. Chem. Soc. 2012, 134, 14070-14077; c) N. Tamai, H. Miyasaka, Chem. Rev. 2000, 100, 1875-1890.

[8] Special issue devoted to polyoxometalates: Cronin, L.; Müller, A. Ed. Chem. Soc. Rev., 2012, $22,7325-7648$.

[9] a) A. Dolbecq, E. Dumas, C. R. Mayer, P. Mialane, Chem. Rev. 2010, 110, 6009-6048; b) I. Izzet, F. Volatron, A. Proust, Chem. Rec. 2016, DOI: 10.1002/tcr.201600092; c) A. Proust, B. Matt, R. Villanneau, G. Guillemot, P. Gouzerh, G. Izzet, Chem. Soc. Rev. 2012, 41, 7605-7622.

[10] B. Wang, Z. D. Yin, L. H. Bi, L. X. Wu, Chem. Commun. 2010, 46, 7163-7165.

[11] a) V. I. Minkin, Chem. Rev. 2004, 104, 2751-2776; b) G. Berkovic, V. Krongauz, V. Weiss, Chem. Rev. 2000, 100, 1741-1753.

[12] A. Saad, O. Oms, A. Dolbecq, C. Menet, R. Dessapt, H. Serier-Brault, E. Allard, K. Baczko, P. Mialane, Chem. Commun. 2015, 51, 16088-16091.

[13] A. Parrot, G. Izzet, A. Proust, O. Oms, A. Dolbecq, K. Hakouk, H. Elbekkachi, P. Deniard, R. Dessapt, P. Mialane, Inorg. Chem. 2013, 52, 11156-11163. 
[14] Acronyms used for the POM hybrids: TBA stands for the tetrabutylammonium counter-ions; K refer to the mono-vacant Keggin-type anion [PW11O39]7-; Sn as subscript indicates the primary functionalization and the term in brackets corresponds to the pending organic moiety on the starting POM platform.

[15] a) D. H. Hu, Z. Y. Tian, W. W. Wu, W. Wan, A. D. Q. Li, J. Am. Chem. Soc. 2008, 130, 1527915281; b) K. Kinashi, Y. Ono, Y. Naitoh, A. Otomo, Y. Ueda, J. Photochem. Photobiol., A 2011, 217, 35-39.

[16] P. Celani, F. Bernardi, M. Olivucci, M. A. Robb, J. Am. Chem. Soc. 1997, 119, 10815-10820.

[17] B. Matt, J. Moussa, L. M. Chamoreau, C. Afonso, A. Proust, H. Amouri, G. Izzet, Organometallics 2012, 31, 35-38.

[18] M. J. Frisch, G. W. Trucks, H. B. Schlegel, G. E. Scuseria, M. A. Robb, J. R. Cheeseman, G. Scalmani, V. Barone, B. Mennucci, G. A. Petersson, H. Nakatsuji, M. Caricato, X. Li, H. P. Hratchian, A. F. Izmaylov, J. Bloino, G. Zheng, J. L. Sonnenberg, M. Hada, M. Ehara, K. Toyota, R. Fukuda, J. Hasegawa, M. Ishida, T. Nakajima, Y. Honda, O. Kitao, H. Nakai, T. Vreven, J. A. Montgomery Jr., J. E. Peralta, F. Ogliaro, M. J. Bearpark, J. Heyd, E. N. Brothers, K. N. Kudin, V. N. Staroverov, R. Kobayashi, J. Normand, K. Raghavachari, A. P. Rendell, J. C. Burant, S. S. Iyengar, J. Tomasi, M. Cossi, N. Rega, N. J. Millam, M. Klene, J. E. Knox, J. B. Cross, V. Bakken, C. Adamo, J. Jaramillo, R. Gomperts, R. E. Stratmann, O. Yazyev, A. J. Austin, R. Cammi, C. Pomelli, J. W. Ochterski, R. L. Martin, K. Morokuma, V. G. Zakrzewski, G. A. Voth, P. Salvador, J. J. Dannenberg, S. Dapprich, A. D. Daniels, Ö. Farkas, J. B. Foresman, J. V. Ortiz, J. Cioslowski, D. J. Fox, Gaussian 09, Gaussian, Inc., Wallingford, CT, USA, 2009.

[19] C. Adamo, V. Barone, J. Chem. Phys. 1999, 110, 6158-6170.

[20] S. Grimme, J. Antony, S. Ehrlich, H. Krieg, J. Chem. Phys. 2010, 132, 154104.

[21] a) E. R. Johnson, A. D. Becke, J. Chem. Phys. 2006, 124, 174104; b) S. Grimme, S. Ehrlich, L. Goerigk, J. Comput. Chem. 2011, 32, 1456-1465.

[22] T. H. Dunning Jr., P. J. Hay, in Modern Theoretical Chemistry, Vol. 3, ed. H. F. Schafer, New York, 1977, pp. 1-28.

[23] A. Bergner, M. Dolg, W. Küchle, H. Stoll, H. Preuß, Mol. Phys. 1993, 80, 1431-1441.

[24] D. Andrae, U. Häußermann, M. Dolg, H. Stoll, H. Preuß, Theor. Chim. Acta 1990, 77, 123-141.

[25] G. J. P. Deblonde, A. Moncomble, G. Cote, S. Bélair, A. Chagnes, RSC Adv. 2015, 5, 7619-7627.

[26] F. Weigend, R. Ahlrichs, Phys. Chem. Chem. Phys. 2005, 7, 3297-3305.

[27] J. Tomasi, B. Mennucci, R. Cammi, Chem. Rev. 2005, 105, 2999-3094. 


\section{COMMUNICATION}

Small cause, big effect. A covalent polyoxometalate(POM)-

benzospiropyran(BSPR) dyad

represents an unprecedented example of a molecular switch that displays specific fluorescence feature in each photochromic form. The fluorescence of the BSPR unit of the POM-based hybrid is considerably enhanced compared to BSPR reference compounds attributed to a more easily accessible emitting state in the hybrid.
Arnaud Parrot, Aurélie Bernard, Aurélie Jacquart, Stefano Artin Serapian, Carles Bo, Etienne Derat, Olivier Oms, Anne Dolbecq, Anna Proust, Rémi Métivier, Pierre Mialane, ${ }^{*}$ and Guillaume Izzet ${ }^{*}$

Page No. - Page No.

Photochromic and Dual-Color Fluorescence in a Polyoxometalatebenzospiropyran Molecular Switch 